\title{
Practical implications of the non-linear pedagogy in future physical Education TeachersTraining during a body expression session: towards the edge of chaos Implicaciones prácticas de la pedagogía no-lineal en la formación del Profesorado de Educación Física durante una sesión de expresión corporal: hacia el borde del caos
}

Teresa Valverde-Esteve

Universidad deValencia (España)

\begin{abstract}
During improvisation in movement, the creativity, emotional and perceptual responses depend on each individual. This study aims to analyse the individuals' performance topics, feelings and response to a specific one-minute classical-style dance improvisation with the given constraint of «magic shoes». The sample was formed by 65 students of theTeacherTraining M aster degree, who wrote down in a diary comments referring to sensations, emotions, attitudes, challenges and cognition after one minute of body expression improvising performance. The performance topics were specially addressed to the inability to perform physical activities that they overcame along their performance. Their diaries also reported their shyness and an open mind to discover new people once they changed their way of thinking, especially when getting closer to others, while other students referred to sensations such as passing from sadness to happiness, shyness to openness, and the attitude of overcoming an obstacle with the help of their classmates. W hen putting thisinto practice, it is suggested that task constraints may increase the movement possibilities during body expression, but al so the deeper cognitive involvement of the students, such as the negotiations of their own boundaries.
\end{abstract}

Key words: Improvisation, emotions, performance, cognition, movement creativity, boundaries.

Resumen. Durante la improvisación en movimiento, las respuestas creativas, emocionales y perceptivas dependen de cada individuo. Esteestudio tiene por objeto analizar en la muestra participante los temas de actuación, sentimientos y la respuesta a una improvisación de danza con música de estilo clástico durante un minuto, con la restricción dada de «zapatillas mágicas». La muestra estuvo formada por 65 estudiantes del Máster de Formación en Profesorado, quienes anotaron en un diario comentarios referidosasensaciones, emociones, actitudes, desafíosy cognición tras la real ización de unaimprovisación deuna actuación durante un minuto de expresión corporal. Los temas de desempeño fueron especial mente dirigidosa la incapacidad para realizar actividades físicas que superaron a lo largo de un desafío. Sus diarios también relataron su timidez, su cambio de mente para descubrir nuevas per sonas una vez cambiada su forma de pensar, especialmente al acercarse alos demás, mientras otros estudiantes se refirieron a sensaciones como el paso de la tristeza alaalegría, la timidez ala apertura de actitud, así como la superación de obstáculos con la ayuda de compañeros. Entre las implicaciones prácticas, se sugiere que las restricciones de latarea pueden aumentar las posibilidades del movimiento durantelassesiones de expresión corporal, así como la participación más cognitiva del alumnado, como la negociación de sus propios límites.

Palabras clave: improvisación, emociones, actuación, cognición, creatividad en movimiento, límites.

\section{Introduction}

The current Spanish Education Act states that the block of contents relating to body expression favours disinhibition and externalization of feelings and emotions. Aspects such as communication, relationships with others and expression are proposed, increasing the complexity of the tasks to achieve greater participation with a spirit of creativity and entrepreneurship. Together

Fecharecepción: 18-09-20. Fechade aceptación: 30-10-20

Teresa Valverde-Esteve

teresa.valverde@uv.es with this block, the transversal elements can be developed simultaneously, favouring respect and tolerancethrough the subject of Physical Education (PE). Therefore, PE teachers endeavour to put dynamic activities into practice, giving students the chance to explore their creativity, mainly through choreographies.

The creative process and its applications to arts and sports have been studied in recent years. In the 1950s in particular the main aims of studies about creativity focused on its precise definition, the instruments used to assess it and certain techniques to favour its development (Sánchez et al., 2003) or on how creativity 
iscomesabout (Sawyer, 2012; Lucznik, 2015). C reativity was defined by Gilford (1950) as the ability to produce numerous valid solutions to a specific problem. Certain properties such as uniqueness, novelty (Hristovski et al., 2011), functionality, originality (being unusual, original, surprising, funny or radically new and reflecting the person's style), impression, logicality or a high number of ideas (Glück et al., 2002) have been attributed to creativity. Therefore, someone creative is characterised by an ability to elaborate and produce diverse ideas (fluency) and be flexible when they are not effective (Guilford and Strom, 1978). O ther traits, such as self-confidence, assertiveness, decision making, self-control, intelligence, knowledge, richness of ideas, inventiveness and imagination, have been attributed to creative people (Glück et al., 2002).

Creations do not necessarily have to be material. We can refer to mental states or structures, events and actions (W reen, 2015; M atas, 2016). For example, dancers use their bodies as an instrument of thought. M ovement isa response to asense or sensory stimulation and the performance is the result of their imagery. In a study conducted by Kirsh (2010), the researchers showed the way dancers use hand marking to carry out mental rehearsals and also to help understand the movement. This fact shows how body and mind are so intimately connected that, due to the nature of dance, there is a very close relationship between the body as a tool and as a medium of creative work (Lucznik, 2015).

Creativity arises while the work is performed and, especially, when there is an interactive process. During the creative process, there are two main mechanisms: divergent thinking to explore and generate new ideas and convergent thinking to test and integrate them (Sawyer, 2012; Blom and Chaplin, 1988; Poutanen, 2013; Lucznik, 2015). The creative processincludesfour major stages: (1) preparation; (2) exploration; (3) illumination; and (4) formulation (Blom and Chaplin, 1988). Preparation involves taking into consideration the performers' needs (López-Tejeda, 2005) and establishing a background. The process of exploration requires conscious control, allowing the person to try, explore and experience many options. Indeed, individuals experience an inner liberation from censorship and prejudice (López-Tejeda et al., 2005). Moments of illumination are characterised by an intensification of sensitivity, memory and thought. The last stage involves giving a solution and, therefore, exposing the inner image (Blom and Chaplin, 1988). Cognitivedisinhibition brings to the association of ideas and is responsible for the «aha!» moment. During this process, introspective filters allow the deepest ideas to emerge (Chaitin et al., 2014).

During an improvisation or spontaneous process, the initial preparation and communication happen almost simultaneously, as inspiration strikes (Blom and Chaplin, 1988; López-Tejeda et al., 2005). Inspiration takes the artist into astate of hyper-excitability, as the old patterns stay away, and they establish something new and unique. As inspiration is autocatalysed by the artist's response to the excitement of creativity, the non-linearity of the situation increases (Kelso, 1997; Zausner, 1996). In the case of dance, improvisation requires the cognition and relationship with one's partner and space (Ribeiro and Fonseca, 2011). The body's response may be conditioned by elements such as experiences, values, tastes, desires and technique (Blom and Chaplin, 1988). Therefore, it is impossible to create ideas if the mind, body and interactions are separated from each other (Aucznik, 2015). In the case of dance, Kirsh (2010) suggests that dancers can mentally establish a structure that is connected to a gesture, dance form or linguistic structure. In case of children, the individuals' skills or motivation may influence their boundaries (Jess et al., 2016).

As observers, these details are important to understand how cooperation between the components of a system creates new patterns in a self-organised fashion (Kelso, 1995). Some aspects, such as the moment at which the idea is thought of and expressed through an action, are still under scrutiny. Indeed, the creative process is considered to be a complex phenomenon (Kirsh, 2010), as body, mind and environment are inseparable and interactive. Complex thinking involves the concepts of flow, coupling, engagement, attractors, affordances, attunement and disturbance, which can improve the experience of activities and increase students' engagement and ecological integration (Storey and Butler, 2013).

From this perspective, complexity theory can also be applied to the movement development (J anemals et al., 2018). Complexity providesanon-linear perspective of the educational process, with particular emphasis on understanding the world and the «self» (Biesta and 0 sberg, 2010). Chow and Atencio (2014) suggested that the complex view of Physical Education is consistent with a non-linear perspective, both of them coinciding in the dynamical systems approach to Physical Education (PE).

According to some authors, complex systems are 
comprised of co-dependent agents, are self-organising, are open to disturbance, are sites of co-emergent learning, are open to varying experiences or interpretations of time and have structures that can be adapted in response to feedback (Storey and Butler, 2013). From a complex thinking perspective, teachers' goals are for the participants in an activity to acquire high levels of engagement and sustainability (Storey and Butler, 2013). Non-linear pedagogy is based on ecological concepts and complex systems theory and it involves applying non-linear dynamics to teaching and coaching (Chow et al., 2006; de Saá Guerra et al., 2016). Nonlinear pedagogy (Frank et al., 2008; A tencio et al., 2014; Gómez-Criado \& Valverde-Esteve) challenges students and collectives to learn within a holistic perspective that involves social, emotional and physical features.

According to W illiams et al.(1999), the most important characteristics of a non-linear dynamical neurobiological systems are a great deal of integration within the system, interconnected and interacting parts or degrees of freedom that result in patterns of movement behaviour, a surprising degree of order between interacting degrees of freedom, an intrinsic self-organising tendency, the ability of subsystems components to influence the behaviour of other subsytems, with variable outputs, and similar system outputs being achieved with different configurations of the system components.

In this regard, non-linear pedagogy (Chow et al., 2006; Chow et al., 2007) involves the manipulation of key elements, understood as the difficulties that we add when we manipulate the tasks (Newell, 1986; Balagué et al, 2013; Torrents et al., 2013; de Saá et al., 2016), which have been shown to enable the emergence of functional behaviours in athletes during sports performance (N ewell, 1986; Chow, 2006; Davids and A raújo, 2009; H ristovski et al., 2011; Greenwood et al., 2012; Storey and Butler, 2013). These perturbations produce bifurcations involving order parameter in terms of learning rates, which some authors describe by several equations (Frank et al., 2008). However, we must be very careful when interpreting and managing the meaning of the outputs and their origin (internal or external). In any system, whatever the type (biological, sports, social system, etc.), the interactions are not static, but dynamic elements that put pressure on the functioning of the system and condition its evolution. Pol et al. (2018) are especially careful in this regard, stressing that constraints act on different levels and timescales.
M otor learning is a process of acquiring movement patterns that satisfy the key constraints on each individual (Davids et al., 2005). Renshaw et al. (2010), evaluated the motor learning approach derived from a constraint-based perspective, examining how a new pedagogical framework could be applied in PE non-linear pedagogy.

Creativity has been shown to occur in the presence and absence of constraints. In fact, working under time pressure is sometimes observed as a positive factor to make artists work (Glück et al., 2002). Some of the conditions that favour creativity are the level of culture, diver sity in a group, trust and a positive climate (Sawyer, 2012; Luczni, 2015). From the PE point of view, constraints are defined as barriers or factors that limit the leisure activity (Patterson, 2001). In some cases, these limitations can reduce enjoyment of the activity due to disabilities (Smith, 1987), structural aspects (family life, season and opportunity), intrapersonal emotional state and interpersonal relationships (Crawford and Godbey, 1987). H owever, Jackson et al. (1993) suggest that constraints must be negotiated in order to overcome obstacles in leisure participation (Patterson, 2001). The task rules may not be physical barriers or limitations that physically eliminate certain responses, but they influence the patterns of movement generated by an individual (Newell, 1986). We must pay sufficient attention to the way participants interpret the imposed tasks, which will therefore lead to the output of different patterns of movement for the same task constraints (N ewell, 1986).

Self-organisation is the spontaneous interaction that leads to the emergence of a new order (Nicolis and Prigogine, 1977; Kauffman, 1995; Bak, 1999; Goodwin, 2002; Solé and Bascompte, 2006; Poutanen, 2013). It refers to more or less spontaneous processes in which external control is not the most important factor. In the case of processes involving several people, the emerging responses are even more evident: the emergence is the product of the interactions. That is, the response to a random or changing environment. Therefore, no techniques are sought to internally organise a complex system. It is simply subjected to different unforeseen tests so that internal answers must befound. Internal mechanismsor interrelationshipsneed to be built or created to allow it to adapt to each case. The more complete the spectrum of external stimuli and the more appropriate moments or times in which these stimuli are presented, the more likely it is that there will be better internal organisation, although 
concepts such as better, worse, good or bad have no meaning here; there is autonomy and personality, among many other features.

Some researchers have analysed skill acquisition, movement and coordination and the relationship of constraints imposed on individuals from two points of view (Patterson, 2001): a traditional and a dynamic perspective. From the dynamic perspective, Newell (1986) refers to the coordination and control of the organism taking into consideration three main properties: organism (anthropometric, cognitive and emotional attributes), environment (such as gravity, temperature and cultural factors) and task (which involvesthe goal of the action or the rules). In thisregard, actions are not caused by constraints; some actions are excluded by them (Kugler et al., 1980; N ewell, 1986). The development of patterns of movement can therefore be considered a permissive rather than a deterministic factor.

The dimensionality of the behaviour is reduced by the interaction of the cooperative elements that form complex systems (Balagué et al., 2013). The complex system perspective helps us to understand the hierarchical structures formed by techniques, tactical strategies, decisions and actions (Balague et al., 2013). Creativity shows different levels of complexity, with more or less proximity to the objective phenomenon and its subjective expression (M atas, 2016). The system's Domain-Field-Individual (DFI) model of creativity (Csikszentmihalyi, 1988) involves three interrelated subsystems that determine creativity: (1) the cultural domain of symbolic rules, (2) the field of disciplinary experts, and (3) the individuals using the system of cultural symbols. As creativity is the sum of the interacting par ts of asystem, social valuescan modify one's creativity (Torrents et al., 2011; Weisberg, 2006; Poutanen, 2013).

Emotions modulate perceptions, intentions and consequently actions, affecting movements in their sensory perceptive essence (Ribeiro and Fonseca, 2011). Dance, as a physical activity, has technical and creative components, as well as an emotional dimension that is closely related to the dancer's movements (Torrents, M ateu, Planas, and Dinusova, 2011). The creative process is usually related to cognition and a linear process that is driven by "possibility thinking» (Torrents, Ric and H ristovski, 2015). Creativity is the synthesis of the emotional, intellectual, physical, perceptual, social and aesthetic aspect of individuals (Lowenfeld and Lambert, 1966). The emotional and perceptual systems are different in each individual. Therefore, professional ssuch as teachers must have sufficient sensitivity to detect variationsin each individual. This processislearnt during interaction, which is better explained through holistic arguments, meaning that the phenomenon under study is a result of many interacting components (Poutanen, 2013). Following trends in non-linear pedagogy, contemporary dance and improvisation focus on exploring, playing and discovering (Torrents et al., 2011). The aim of this study was to identify the participants' movement response and feeling response during a specific one-minute classical musical style dance improvisation under the imposed task constraint of wearing «magic shoes» in order to optimise performance.

\section{Methods}

\section{Participants}

The sample was formed by 65 ( $22.8 \pm 1.2$ years) students from the master's course in Secondary Teacher Training who participated in the activity. All of them had previously studied the Degree in Sports Sciences and Physical Activity. None of them had professional experience in dancing or arts.

\section{Instruments}

The results of this activity followed a qualitative analysis. For this purpose, students wrote down in a diary the reports after this experience. Data were codified and classified in categories, after the simplification, abstract and selection of the information. These categories responded to the following criteria: a) what did they perform, b) how did they feel, c) what change did they experience.

\section{Parameters evaluated}

Shape of creativity in movement, emotions, sensations (with oneself and with others), actions (representations, liberation of feelings, fears, attitudes, challenges, knowledge), following the criteria proposed by Glück et al. (2002), also taking into consideration the studies by N ewell (1986) and Kirsh (2010).

\section{Procedure}

This specific activity was held in an annual compulsory subject named «Physical Education Learning and Teaching», whose aim is to provide students experiences, procedural skillsand pedagogical resources which, in the future, allow them to design, apply and evaluatethe PE in Secondary Education in an autonomous 
way. This subject seeks to foster the critical and reflexive capacity of the students and to stimulate their involvement in the learning process. In this regard, a feedback in the diary of the subject is required, so that students have the opportunity to write down their ideas and express themselves in a more comfortable way, apart from the opportunity that they have after the performance of the sessions.

To favour a participative environment, in the specific module of the Body Expression contents, students got previously familiar with the contents that were about to develop in future sessions and would take them away from their comfort zone. There were eight total sessions in which the professor aimed to enhance the students' disinhibition regarding emotions, feelings attitude, challenges and cognition by fostering respect, empathy, flow and creativity. These concepts were previously introduced following the curriculum of Secondary Education. However, more concepts came out as the students got involved in the activities. Lastly, they reached the highest level of complexity in the activities performed, which was to develop spontaneous improvisation with music and with a given constraint, named «the magic shoes».

The procedure was related to the goal of the task and rules specifying or constraining response dynamics (Newell, 1986), and consisted of performing a oneminute motor improvisation. All the students were positioned in a circle and the order of participation was random. That is to say, it was the students themselves who decided when and in what order they wanted to go up and perform improvisation as their classmates ended their minute of performance. No free time was allowed between the minutes of performance. All students were watching and quietly paying attention to their classmates' improvisations.

The instruction was that each of them had some «magic shoes» that changed something in them when they put them on. The entire compact disc of «The M agic Flute» by Mozart, K 620 (acts I and II, performed by Vienna Philharmonic O rchestra, conducted by Karl Böhm, 1955) was played on the speakers of the sports hall to create a respectful atmosphere and also to boost activation, motivation and concentration throughout the performance.

During the explanation of the activity, the essential limits of motor task, space (axes, planes, volume) and time were established to improve body movement (Torrents et al., 2011). Students were encouraged to carry out original activities and a positive environment was created by the teacher to motivate creative thinking (Lucznik, 2015; Zeibig, 2015).

The experience and data were collected and analysed through an individual compulsory diary in which the students wrote the answers to the following semistructured questions: «how did you feel during the magic shoes performance?» and «what was the change that you experienced onceyou put on your shoes?». The first phase of the data analysis consisted of processing, segmentation and coding of data collection techniques (Kuckartz, 2013). During the second phase, the abstraction, interpretation and categorisation of the established codes was performed. The answers were categorised as in the study by Glück et al. (2002), according to sensations, emotions, attitudes, challenges and cognition. Oral feedback was briefly given by the teacher and students once all the performances had taken place in order to foster information flows and increase randomness and serendipity (Poutanen, 2013).

\section{Results}

The teacher observed how students were respectful to each others and also how they showed very different motor responses during the «magic shoes» activity, as no repetition was allowed in the performance. M ost of the actions concerned the performance of their sports, injuries, disabilities or slowness to wake up. The most common patternswere inability to play soccer, basketbaII, athletics, rugby, dance (all styles), and even their inability to perform certain physically-demanding activities (such as jumping, doing push-ups or running a marathon) and the ability they acquired once they put on their shoes.

«It was an activity where each of us was able to develop the knowledge of body expression that we had seen in previous sessions. It was an activity where we had to express, feel, communicate, develop in space... useall theelements of a possible body expression Didactic Unit» (P-03)

Some students also interpreted a physical disease, disability or injury that had marked a turning point in them and the sensations of overcoming this once they had recovered or how their attitudes changed with the help and support of their classmates. In two cases, the students asked a classmate to help them move as if they were marionettes or to show how could they change their movements with the aid of a partner.

«...the opportunity to express a thought I had inside me about the current state of society» (P-22)

«t scared me to do a minute of acting al one but in the end, 
it was very rewarding. I chose to represent someone who couldn't move their legs and who when walking, put on their shoes and could walk. I think of it as a representation that reflects the difficulties that many people have in their day-to-day lives of which we are unaware. Somehow, I wanted to show it and it was the best opportunity. Also, dreaming that there are some magic shoes that achieved this, makes us move on» (P-36).

Some students expressed being tired when they get up and suddenly having a lot of energy to take the bus, or other situations such as attending lectures, going to work, being very friendly to neighbours or having good luck (in situations such as winning the lottery, fishing, passing an exam or owning a new property).

0 ther deeper responses were performed by other students, who showed their shyness and an open mind to discover new people once they changed their way of thinking, especially when talking to others, while other students referred to sensations such as passing from sadness to happiness, shyness to openness, and the attitude of overcoming an obstacle with the help of their classmates, the ability to navigate abroad, and discovering a new horizon or a stolen treasure.

«... It wasa complex activity at an emotional level... » (P22)

«... it was an exercise that consisted in abstracting from reality, because if I thought about the rest looking at me, I would feel nervous, so I forgot about it» (P-09)

Students' answers were classified by the researchers after a careful reading of the students' diary. They are shown in table 1.

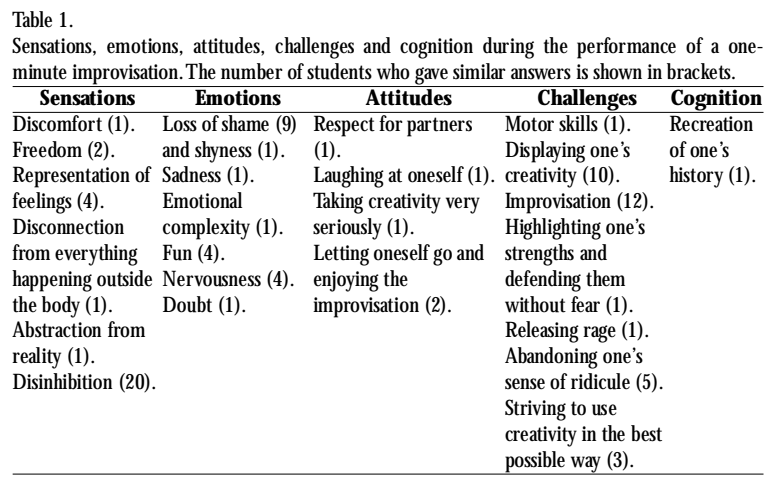

Students also reported some changes that they experienced after the performance of this activity.

«... this activity helped meto disinhibit myself and to strive to use my creativity in the best possible way» (P-42).

"This activity helped me to expose myself to the components of the class, consequently requiring a control of emotions) (P. 52).

«...this practicehelped me to improve improvisation, and to be able to see that I am able to do things in which I did not feel comfortable doing them» (P-11).

«lt was an activity to improve my knowledge about improvisation and body expression. And, above all, it caused me to take very seriously what a priori was an unimportant activity. Therefore, this activity managed to get me into the role of my little performances (P-12).

«It was a minute of freedom to express everything I felt at that moment»(P-15).

\section{Discussion}

Movement is both expressive and practical. It contributes to human growth and development. It is a fact that our bodies respond to unspoken needs and desires, interpreting the continuous flow of internal and external signals and determining the appropriate form of action (Blom and Chaplin, 1988). For this reason, there is a specific area in the Primary Teaching degree, as well as in the Secondary Teaching Masters, which special ises in the Didactics of Body expression, with an emphasis on the development of disinhibition in future teachers and on making their students feel comfor table.

Body expression and the parameters involved in its performance and assessment are some of the most complex tasks that students and referees can undertake. During this activity, creativity and experience are combined to produce a performance that can either be established, such as choreography or improvised, as in the case of this study. To bring creativity into practice (Torrance, 2003) defined creativity as a process that involves being sensitive to problems, deficiencies and gaps in knowledge. Also, this process needs to identify difficulties, seek solutions, make speculations or formulatehypotheses. Different research showsastrong relationship between neuroscience and creative musical activity. Its practice generates connections between areas of the brain linked to creativity and movement, emotions or the interactions generated by these movements (Addessi et al., 2015).

According to Hristovski et al. (2011), individual creativity is the result of the interaction of three nonlinear properties: cause-effect, non-proportionality, constraint control and multi-stability in complex systems. Behavioural structures are created from novel forms of movement in a self-organised system. In this regard, concepts of self-organisation explain synergies in human coordination through motor programmes or schemas (Balagué et al., 2013).

There are no guarantees in advance that everything will work well (in the way of producing creative 
movements as we cannot predict the results), but we can notice if there is a fluency in the lesson dynamics. Each organism is different and the internal resources (physical, psychological, character, cultural, etc.) are not directly accessible. Therefore, simply by observing the results, we can analyse their functioning. That is, the professional must know in advance that the result of the training process is not totally predictable and must be sufficiently open-minded or relaxed to evaluate the result achieved without prior judgment. However, we can consider whether if the answer is in accordance with the proposed task. It is important that chance, everyday life, errors, unforeseen events, etc. intervene. Selforganisation is something that show up better in the limit between order and chaos; therefore, a task can follow a mechanical order without any other answer possibility but it does not necessarily have to follow an order, and the other way round. The sensorial perception of the performance depends on how the body feels and works, what it desires, does and suffers (H ristovski et al., 2011; Schuterman, 1999; Ribeiro and Fonseca, 2011).

Intra-personal and inter-personal actions are continuously enriching the culture of movement through sports and physical activities, enhancing performance through the intervention of new movement patterns(Hristovski et al., 2011). In such an environment, as perception is linked to the body, the theory of situated cognition recognises that the agent and context are continuously co-built (Ribeiro and Fonseca, 2011). This study was conducted in a PE setting that was familiar to participants, as many elements such as baskets, mats or wall bars were present. This may be the reason why most of the participants decided to perform activities related to the enhancement of their sports performance or injuries and disabilities that had constrained their practice.

Motor cognition provides information about the individual action that is about to take place. The role of motor cognition and motor resonance makes the motor system act in a perceptive manner. Therefore, movement has its own adaptive intelligence (Ribeiro and Fonseca, 2011). We consider that participants adapted what they expected to perform to the situation and formality, according to the social code established and overcoming the filter of prejudices. Pattern complexity shows how a given pattern adjusts to changing internal or external conditions (Kelso, 1995). In this case, it is not only a matter of thinking, but also adapting to what previous classmates had al ready done, bringing participants out of the comfort zone. Therefore, loss of stability leads to the emergence of different patterns. After the performance, most of the participants reflected that they were amazed by what they had done and the impossibility of repeating this action in another context.

Dance is an interesting context in which non-linear sport scientists can study emergent and non-linear behaviours (Torrents et al., 2011; Balague et al. , 2013) It can be seen that emergent properties are present in all complex systems in nature (Kelso, 1995). M oreover, what is important is to identify some of the key processes involved in emergence. The analysis of these proposals makes it possible to generate multiple and individual learning and coaching strategies, escaping from the classical methodologies that characterise physical, technical or tactical intervention programmes (Balagué et al., 2013). In addition to the movement response, we also wanted to discover the sensations, emotions, attitudes, challenges and cognition experienced during the improvisation in order to focus on these processes to increase the acquisition of the established competences in the future. Indeed, the theory of selforganised pattern formation in non-equilibrium systems also puts creativity in a new light (Kelso, 1995), as the emergence of patterns is necessary but is not a sufficient condition for creativity (H ristovski et al. , 2011; Balagué et al., 2013).

Kirsh (2010) suggests that imagination is the result of a combination of the senses and the body. In the case of dancers' performance, they think in real time and creativity has been pre-planned, sequentially processed in their minds and simplified through divergent and convergent thinking. These students had no time to preplan their choreography as they were asked to improvise and the situation itself required them to discard certain ideas as they watched their partners' performance, as no entire repetition of choreographies was allowed. In fact, some students pointed out that their ideas were adapted and modified during the improvisation. This phenomenon shows how they adapt to the loss of stability and to new situations.

Improvisation is an affective cognitive experience that takes place in and through the body. During improvisation, an ephemeral organisation of movements arises, as these structures do not get to be established and used later. Therefore, what is important is to keep oneself in a process of inventing new problems, thus generating new actions by combining elements of time, space and weight. A relationship will be established with rules, space, stage partners, audience, music, lighting, 
costumes, etc. (Ribeiro and Fonseca, 2011). W hat happens when we move involves an intricate network of non-linearly coordinated functions (Balague et al., 2013), as one momentum may demand the next (Blom and Chaplin, 1988). The response dependson a conscious experience of the body in space and time, sound, visual and tactile environments (Ribeiro and Fonseca, 2011). During improvisation, the communicative aspect of the moment is capitalised and the co-movers or watchers will respond to the universal language that is being expressed (Blom and Chaplin, 1988). In this study, the participants showed that their individual idea remained the same during the one-minute performance. Curiously, no connection was established with the improvisations of students' classmates. That is to say, participants did not show a continuing story following on from the previous participant. It was the first time they were asked to do a one-minute performance and we could see that many participants were not really paying attention to every single movement of their classmates' performances but were thinking of their own ideas and changing what had already been used as an idea to produceamorecreativeperformance. Kirsh (2010) suggests that during dancing improvisation there is a high degree of interactive activity, as the characters explore, select and increase the development of dance material.

In this regard, Balagué et al. (2013) suggested that new proposals make it possible to generate multiple individual learning strategies, avoiding the classical methodologies that characterise physical, technical or tactical intervention programmes. As reported by G lück et al. (2002), the more constraints a creative person faces in their work, the greater their ability to produce something creative, while fulfilling external demands. That is one of the factors that we believe made all the students perform the task. Multiple solutions are always needed for innovative behaviour (Hristovski et al., 2011). Therefore, the acquisition of new patterns can attract certain order parameters, following non-linear dynamic frameworks.

The introduction of constraints is reported not to affect the number of degrees of freedom, as they are simply alternatives (Kluge et al., 1980), or to reduce the possible dynamic responses resulting in optimal selforganisation (Newell, 1986). The possibility of adding «magic shoes» to their improvisation encouraged students to present the relevant information, with Physical Education as a common theme. We can simplify motor responses as topics concerning physical and mental health and illness or pain. The important part of this performance was that performers optimised their task within the imposed constraints (Newell, 1986).

Creative cognition happens as a result of abstract thinking and sensing, feeling and doing (Kirsh, 2010). The action is not performed under the full control of consciousness; it should be felt as a conglomerate of many surprising sets of actions that have been slowly disentangled (Latour, 2005). The experience of positive emotions and promotion of well-being during the practice of body expression were reported by Torrents et al. (2011). Specifically, introspective activities had an impact related to happiness and surprise, whereas staging tasks reported joy and those performed in pairs or with body contact were related to love and wellbeing (Torrents et al., 2011). Coinciding with the students, the samplein the study byTorrentset al. (2011) perceived the activity as positive and highlighted the possibility of getting to know their classmates better and the loss of their sense of embarrassment.

We should point out that intrinsic motivation within students is necessary to conduct a project in the face of internal and external difficulties (Glück et al., 2002). Indeed, to formulate ideas and perform them, it is necessary to overcome the entire filter of prejudices and act according to the val ues that have been agreed in the class atmosphere, such as respect for others. These students showed a high level of respect for their classmates and once the performance was finished, they reported in the diary that they «felt the support of their classmates and teacher».

Putting this into practice for teachers, creativity must be directed in order to determine and discover contradictions in students when responding to practical problems. To increase students' creativity (originality, flexibility, elaboration, curiosity, sensitivity and independence), the development of certain ways of thinking, work tools and aspects of living in society are suggested by Matas (2016). As reported by Storey and Butler (2013), research is conducted to support teachers, coaches and researchers in helping students to learn more effectively and efficiently. From thisstudy, teachers can discover a practical way of developing motor creativity, from inner liberation from censor ship through to the complexity perspective. Non-linear pedagogy proposes the introduction of constraints to develop movement strategies that are conducted in order to explore permissions to certain performances instead of direct solutions to traditional assignment tasks, which are aimed more at the determination of a procedure and result. 
In conclusion, the individuals' improvisation and body expression as a consequence of the addition of task constraints generate a variety of responses that, once detected, can be analysed and improved. Motor responses to ideas have a positive impact on the participants by enhancing their sensitivity to some aspects that can be transferred to their daily tasks. Their perception of their own and their classmates' sensations, emotions, attitudes, challenges, cognition and boundaries are stimulated in a way that results in a motor response and makes them more respectful to others. However, more studies are needed to analyse movement patterns according to inner censorships and thoughts and also to constrain the previous participant's task or environment to ask the following participant for new adaptations. It could also be assessed how the movement and attitude parameters vary when we modify the order, the number of individual performances or the style of music.

\section{Acknowledgements}

The author would like to thank Conselleria de Innovación, Universidades, Ciencia y Sociedad Digital (Generalitat Valenciana, Best/ 2019/ 110), Fulbright Comission and University of Valencia grants.

\section{References}

Addessi, A. R., Maûolli, M., and Annelli, F. (2015). The MIROR Platform forYoung Children's Music and Dance Creativity: Reûexive Interaction meets Body-gesture, Embodied Cognition, and Laban Educational Dance. Journal of the Early Childhood M usic and M ovement Association, 10 (1), 1-8.

Atencio, M., Yi, C. J., Clara, T. W. K., and Miriam, L. C.Y. (2014). U sing a complex and nonlinear pedagogical approach to design practical primary physical education lessons. European Physical Education Review, 20(2), 244263.

Bak, P. (1999). How NatureWorks: the science of self-organized criticality. (2. ${ }^{a}$ ed.). Springer-Verlag

Balagué, N., Torrents, C., Hristovski, R., Davids, K., andA raújo, D. (2013). 0 verview of complex systems in sport. Journal of Systems Science and Complexity, 26(1), 4-13.

Biesta, G., and O sberg, D. C. (2010). Complexity, education, and politics: From the inside out and outside in. Sense Publishers.

Blom, L. A., and Chaplin, L.T. (1988). Themoment of movement: Dance improvisation. Pittsburg: University of Pittsburgh Pre.

Chaitin, G. , Chaitin, V., and A brahão, F. S. (2014). M etabiology: the origins of biologic creativity. Investigación y Ciencia.

Chow, J.Y., and Atencio, M. (2014). Complex and nonlinear pedagogy and the implications for physical education. Sport, Education and Society, 19(8), 1034-1054.

Chow, J.Y., Davids, K., Button, C., Shuttleworth, R., Renshaw, I., and Araujo, D. (2006). Nonlinear pedagogy: a constraints-led framework for understanding emergence of game play and movement skills. Nonlinear dynamics, psychology, and life sciences, 10(1), 71-103.

Chow, J.Y., Davids, K., Button, C., Shuttleworth, R., Renshaw, I., and Araújo, D. (2007). The role of nonlinear pedagogy in physical education. Review of Educational Research, 77(3), 251-278.

Crawford, D. W., and Godbey, G. (1987). Reconceptualizing barriers to family leisure. Leisure sciences, 9(2), 119-127.

Crawford, D. W., Jackson, E. L., and Godbey, G. (1991). A hierarchical model of leisure constraints. Leisure sciences, 13(4), 309-320.

Csikszentmihalyi, M . (1988). M otivation and creativity:Toward a synthesis of structural and energistic approaches to cognition. N ew Ideas in psychology, 6(2), 159-176.

Davids, K. and Araújo D (2010). The concept of ' $O$ rganismic Asymmetry' in sport science, Journal of Science and Medicine in Sport, 7, 633-640.

Davids, K., Chow, J. Y., and Shuttleworth, R. (2005). A Constraints-based Framework for N onlinear Pedagogy in Physical Education1. New Zealand Physical Educator, 38(1), 17-29.

de Saá Guerra,Y., Sarmiento M ontesdeoca, S., GarcíaM anso, J. M., M artín González, J. M., Navarro Valdivielso, M., Rodriguez Ruiz, D., ... Q uiroga Escudero, M. (2016). Exercise and Alzheimer's: The body as a whole. Revista Andaluza de Medicina Del D eporte, 10(3), 120-124.

Frank, T. D., Michelbrink, M., Beckmann, H., and Schöllhorn, W. I. (2008). A quantitative dynamical systems approach to differential learning: self-organization principle and order parameter equations. Biological cybernetics, 98(1), 19-31.

Glück, J., Ernst, R., and Unger, F. (2002). How creatives define creativity: Definitions reflect different types of creativity. Communication Research Journal, 14(1), 55-67.

Gómez-Criado, C., \&Valverde-Esteve, T. N onlinear pedagogy and its application in a volleyball didactic unit: a practical approach (La pedagogía no lineal y su aplicación en una unidad didáctica de voleibol: un enfoque práctico). Retos, (39), 805-810.

Goodwin, B. (2002). How the Leopard Changed Its Spots. [Las Manchas Del Leopardo]. Tusquets Editor.

Greenwood, D., Davids, K., and Renshaw, I. (2012). How elite coaches' experiential knowledge might enhance empirical research on sport performance. International Journal of Sports Science and Coaching, 7(2), 411-422.

Guilford, J. P. (1950). Creativity. American Psychologist, 5(9), 444-454.

Guilford, J. P., and Strom, R. D. (1978). Creatividad y educación. Paidós.

Hristovski, R., Davids, K., Araujo, D., and Passos, P. (2011). 
Constraints-induced emergence of functional novelty in complex neurobiological systems: abasisfor creativity in sport. Nonlinear Dynamics Psychology and LifeSciences, 15 (2), 175-206.

Jackson, E. L., Crawford, D.W., and Godbey, G. (1993). Negotiation of leisure constraints. Leisuresciences, 15(1), 1-11.

Janemalm, L., Q uennerstedt, M., and Barker, D. (2018).W hat is complex in complex movement? A discourse analysis of conceptualizations of movement in the Swedish physical education curriculum. European Physical Education Review, $1-15$.

Jess, M. , Keay, J., \& Carse, N. (2016). Primary physical education: A complex learning journey for children and teachers. Sport, Education and Society, 21(7), 1018-1035.

Kauffman, S. A. (1995). At H omein theU niverse:TheSearch for Laws of Self-O rganization and Complexity. 0 xford U niversity Press.

Kelso, J. S. (1995). Dynamic patterns:Theself-organization of brain and behavior. Cambridge, M A: MIT Press

Kirsh, D. (2010). Thinking with external representations Ai and Sodety, 25(4), 441-454.

KuckartzU (2013). Q ualitativeTextAnalysis: A guideto M ethods, Practiceand U sing Software. SAGE Publications.

Kugler, P. N., Kelso, J. S., andTurvey, M. T. (1980). O n the concept of coordinativestructuresasdissipativestructures: I.Theoretical lines of convergence. Tutorialsin motor behavior, 3, 3-47.

Latour, B. (2005). Reassembling the social: An introduction to actornetwork-theory. 0 xford U niversity Press.

LópezTejeda, A. (2005). Lacreatividad en las actividades motrices. Apunts, 20-28.

Lowenfeld,V. and Lamber, Brittain (1966). CreativeM ental G rowth (4thed). Macmillan.

Aucznik, K. (2015). Between mindsand bodies: Someinsights about creativity from danceimprovisation. TechnoeticArts, 13(3), 301-308.

Torrents, C., H ristovski, R., and Balagué-Serre, N. (2013). Crea tividad y emergenciaespontáneade habilidades de danza. $R e$ tos: nuevas tendencias en educación física, deporte y recreación, (24), 129-134.

Newell, K.M. (1986). Constraintson thedevelopment of coordination. In M.G.Wadeand H.T.A.W hiting (Eds), M otor development in children:Aspects of coordination and control, pp. 341-361. MartinusNijhoffPublishers.

Nicolis, G., and Prigogine, I. (1977). Self-Organization in N onequilibrium Systems: From Dissipative Structures to Order through Fluctuations ( $1 .{ }^{a}$ ed. $)$. JohnW iley and Sons.

Patterson, T. S. (2001). Constraints: An integrated view point. Illuminare, 7(1), 30-38.

Pol, R., Hristovski, R., M edina, D. , and Balague, N. (2018). From microscopic to macroscopic sports injuries. Applying the complex dynamic systems approach to sports medicine: a narrativereview. British Journal of SportsM ediane, 53(19), 12141220.

Poutanen, P. (2013). Creativity asseenthroughthecomplex systems perspective. Interdisciplinary Studies Journal, 2 (3), 207-217.

Renshaw, I., Chow, J.Y., Davids, K., and Hammond, J. (2010). A constraints-led perspectiveto understanding skill acquisition and game play: A basisfor integration of motor learning theory and physical education praxis?. Physical Education and Sport Pedagogy, 15(2), 117-137.

Ribeiro, M. M., and Fonseca, A. (2011). The empathy and the structuring sharing modes of movement sequences in the improvisation of contemporary dance. Research in Dance Education, 12(2), 71-85.

Sánchez, M. D. P., Martínez, O. L., García, C. F., and García, M. R. B. (2003). Adaptación delapruebafigurativadel test depensa miento creativo deTorranceen unamuestradeal umnosdelos primerosniveles educativos. Revista deinvestigación Educativa, 21(1), 201-213.

Sawyer, R. K. (2012). The science of human innovation: Explaining creativity. 0 xford U niver sity Press.

Shusterman, R. (1999). Somæesthetics: A disciplinary proposal. The Journal of aestheticsand art criticism, 57(3), 299-313.

Smith, R. W. (1987). Leisure of disable tourists: Barriers to participation. Annals of tourism research, 14(3), 376-389.

Storey, B., and Butler, J. (2013). Complexity thinking in PE: gamecentred approaches, gamesascomplex adaptivesystems, and ecological values. Physical Education and Sport Pedagogy, 18 (2), 133-149.

Torrance, E. P. (2003). Reflection on emerging insights on the educational psychology of creativity. The educational psychology of creativity, 273-286.

TorrentsM artín, C., Ric, Á., and H ristovski, R. (2015). Creativity and emergence of specific dancemovementsusinginstructional constraints. Psychol ogy of Aesthetics, Creativity, and theArts, 9(1), 65-74.

Torrents, C., Castañer, M., andAnguera, M. .T. (2011). Dancing with complexity: 0 bser vation of emergent patternsin dance improvisation. Education, Physical Training, Sport, 80(1), 76-81.

Solé, R., and Bascompte, J. (2006). Self-organization in complex ecosystems. Princeton: Princeton University Press.

Torrents, M ateu, Planas and Dinosôva(2011).Thepossibilities of expressive movement and creative dance tasks to provoke emotional responses. Revista de Psicología del Deporte, 20(2), 401-412.

Valero-M atas, J. A., Valero-0 teo, I., Coca, J. R., and Laurencio Leyva, A. (2016). Creatividad y educación parael siglo XXI desdeunaperspectivasociológica. Revista del nvestigacionesPolíticasy Sociológicas, 15(2), 201-222.

Weisberg, R. W. (2006). Creativity: Understanding innovation in problem solving, science, invention, and thearts. JohnW iley and Sons.

W illiams,A.M ., K. Davids, andJ.G.W illiams (1999). Visual perception and action in sport. E and FN Spon.

W reen, M. (2015). Creativity. Philosophia,43, 891-913.

Zausner, T. (1996). Thecreativechaos: Speculations on theconnection between non-linear dynamics and the creative process. InW. Sulis andA. Combs (Eds), N onlinear dynamicsin human behavior (pp. 343-349). River Egde.

Zeibig, D. (2015). Estrategiasparaun pensamiento creativo. M ente y cerebro, (70), 36-41. 